\title{
Dietary patterns and cognitive ability among 12- to 13 year-old adolescents in Selangor, Malaysia
}

\author{
Abdul Razak Nurliyana ${ }^{1}$, Mohd Taib Mohd Nasir ${ }^{1, *}$, Mohd Shariff Zalilah ${ }^{1}$ and \\ Abdullah Rohani ${ }^{2}$ \\ 'Department of Nutrition and Dietetics, Faculty of Medicine and Health Sciences, Universiti Putra Malaysia, \\ 43400 UPM Serdang, Selangor, Malaysia: ${ }^{2}$ Department of Human Development and Family Studies, Faculty of \\ Human Ecology, Universiti Putra Malaysia, Serdang, Selangor, Malaysia
}

Submitted 29 May 2013: Final revision received 26 November 2013: Accepted 14 January 2014: First published online 10 February 2014

\begin{abstract}
Objective: The present study aimed to identify dietary patterns and determine the relationship between dietary patterns and cognitive ability among 12- to 13 year-old Malay adolescents in the urban areas of Gombak district in Selangor, Malaysia. Design: Data on sociodemographic background were obtained from parents. Height and weight were measured and BMI-for-age was determined. Adolescents were interviewed on their habitual dietary intakes using a semi-quantitative FFQ. Cognitive ability was assessed using the Wechsler Nonverbal Scale of Ability in a one-to-one manner. Dietary patterns were constructed using principal component analysis based on thirty-eight food groups of the semi-quantitative FFQ.

Setting: Urban secondary public schools in the district of Gombak in Selangor, Malaysia.

Subjects: Malay adolescents aged 12 to 13 years ( $n$ 416).

Results: The mean general cognitive ability score was 101·8 (SD 12•4). Four major dietary patterns were identified and labelled as 'refined-grain pattern', 'snackfood pattern', 'plant-based food pattern' and 'high-energy food pattern'. These dietary patterns explained $39 \cdot 1 \%$ of the variance in the habitual dietary intakes of the adolescents. The refined-grain pattern was negatively associated with processing speed, which is a construct of general cognitive ability. The highenergy food pattern was negatively associated with general cognitive ability, perceptual reasoning and processing speed. Monthly household income and parents' educational attainment were positively associated with all of the cognitive measures. In multivariate analysis, only the high-energy food pattern was found to contribute significantly towards general cognitive ability after controlling for socio-economic status.

Conclusions: Consumption of foods in the high-energy food pattern contributed towards general cognitive ability after controlling for socio-economic status. However, the contribution was small.
\end{abstract}

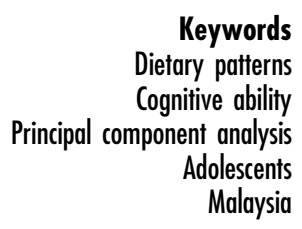

Adolescence is a transitional period where the brain matures to achieve its adult structure and functions ${ }^{(1)}$. During this period, a major transformation occurs in the prefrontal areas of the brain, where there is a decline in the grey matter and an increase in the white matter ${ }^{(2)}$. The prefrontal areas of the brain are associated with higherorder cognitive functioning which includes reasoning, planning, decision making and execution of goal-directed behaviour $^{(3)}$. Like any other organ, the brain is constructed from carbohydrate, protein, fat, vitamins and minerals ${ }^{(4)}$. These nutrients are supplied through the diet and account for both structure and functions of the brain ${ }^{(4)}$.

Previous studies have examined the effect of specific nutrients on cognition; for example, provision of glucose ${ }^{(5)}$ and micronutrients ${ }^{(6,7)}$ in improving cognitive functioning of school-aged children. Although supplementation has been found to benefit cognition among undernourished children, the findings were inconsistent among wellnourished children ${ }^{(8)}$. This might be due to the complexity of diets and the interrelationships among nutrients and foods that complicate the effects of a single dietary component on health outcomes ${ }^{(9)}$.

Typically, people do not consume isolated nutrients; instead they consume meals that consist of many foods with combinations of nutrients ${ }^{(10)}$. Dietary patterns describe how foods and nutrients are consumed in combination, and may be able to provide a comprehensive assessment between diet and health outcomes ${ }^{(10)}$. 
Thus, dietary pattern analysis has become a recent interest in relating diet as a whole rather than specific nutrients to health outcomes ${ }^{(11)}$. Dietary patterns can be derived through statistical analysis that is based on the collinearity of nutrients and foods ${ }^{(10)}$. Factor analysis, cluster analysis and dietary indices are the most common methods used in deriving dietary patterns ${ }^{(10)}$. Dietary pattern scores represent the level of adherence to the pattern $^{(12)}$. Dietary patterns also reflect individual preferences for foods, as more consumption of some foods may usually indicate less consumption of other foods ${ }^{(13)}$.

In the UK, results from the Southampton Women's Survey (SWS) and the Avon Longitudinal Study of Parents and Children (ALSPAC) have shown that dietary patterns in infancy tend to influence cognitive ability in child$\operatorname{hood}^{(14,15)}$. Children whose diet in infancy was consistent with the infant dietary guidelines pattern, which was characterized by high consumption of fruits, vegetables and home-prepared foods, were found to have better cognitive ability at the age of 4 years than children whose diet in infancy followed the 'adult foods' pattern characterized by high consumption of bread, savoury snacks, biscuits, squash, breakfast cereals and chips ${ }^{(14)}$. Among adolescents, a Western pattern that was characterized by high intakes of takeaway foods, confectionery and red meat was found to be associated with higher behavioural problems ${ }^{(16)}$. An unhealthful eating pattern characterized by high consumption of sweets and fried foods was found to be associated with poorer school performance ${ }^{(17)}$.

Nutrition plays an important role in cognitive development in the rapid growth period during childhood as it provides the building blocks for neural formation and brain development ${ }^{(18)}$. Inadequate diet and malnutrition during this developmental stage may have lasting negative effects on cognitive development ${ }^{(18)}$. For example, in a longitudinal study in south-east Michigan in the USA, low-birth-weight children were found to have persistently lower cognitive ability throughout their childhood and adolescence than their normal-birth-weight counterparts regardless of socio-economic status ${ }^{(19)}$. Nutrition continues to influence short-term cognition, through the provision of energy and nutrients to support cognitive functioning, throughout life ${ }^{(18)}$. Adolescence is an important period where physical and social changes influence eating behaviours and nutritional status ${ }^{(20)}$. Dietary practices during this period may have implications for health later in adult life ${ }^{(20)}$. For example, dietary patterns that developed during this period may lead to overweight and eating disorders in adulthood ${ }^{(21)}$. In many countries, adolescents' diets have been found to be inconsistent with the dietary guidelines ${ }^{(11)}$. Although there are many studies on dietary intakes among adolescents in Malaysia, to our knowledge there is no publication on dietary patterns of adolescents in Malaysia derived from multivariate analysis. In other countries, only recently have studies started to examine the association between dietary patterns and cognitive ability, mostly among infants and children ${ }^{(14,15,17)}$. Therefore, in the present study we aimed to determine the dietary patterns of a group of Malaysian adolescents and the associations between dietary patterns and cognitive ability of the adolescents.

\section{Methods}

\section{Participants and procedures}

Adolescents aged 12 to 13 years ( $n$ 416; 161 males, 255 females) were recruited from five out of twenty-three urban secondary public schools in the district of Gombak in Selangor, Malaysia. The schools were randomly selected based on a list of public secondary schools registered in Selangor as of 31 January $2011^{(22)}$. Four out of ten or eleven Secondary 1 classrooms from each school were randomly selected and all students in the selected classes were invited to participate in the study. Permission to conduct the study was obtained from the Ministry of Education Malaysia and Selangor State Department of Education. Ethical approval was obtained from the Medical Research Ethics Committee, Faculty of Medicine and Health Sciences, Universiti Putra Malaysia. Informed consent was obtained from both parents and adolescents who agreed to participate in the study. Only Malay adolescents were included due to language barriers in explaining food consumption to adolescents of other ethnicities.

The population in Gombak District was 629971 in the 2010 Population and Housing Census of Malaysia, consisting of $62 \cdot 0 \%$ Malay, $23 \cdot 4 \%$ Chinese, $12 \cdot 2 \%$ Indian and $2 \cdot 4 \%$ from other ethnicities ${ }^{(23)}$. By including only Malay adolescents in the study, about $38.0 \%$ of the population was excluded. A total of 600 adolescents from five selected public secondary schools in the urban areas of Gombak, Selangor were invited to participate in the study. Initially there were 421 adolescents who signed up to participate; however, five did not complete the study. Thus only 416 adolescents participated, giving a response rate of $69 \cdot 3 \%$.

A questionnaire on sociodemographic background was sent to parents and collected at each school a week before commencement of the study. Completion of the questionnaire was determined on the day that the questionnaire was collected and the information given was crosschecked with the school registry. Parents with incomplete forms were called to answer the questions by telephone. Data from the adolescents were collected in a counselling room of each of the schools from July 2011 to March 2012. Height and weight of the adolescents were measured using standard procedures on the same day. They were also interviewed on their intakes of ninety-six food items over the past month using a semi-quantitative FFQ. Cognitive assessment was then conducted in a one-to-one manner. 


\section{Sociodemographic background and characteristics of the sample}

Sociodemographic background was obtained from parents through a questionnaire which sought information on their educational attainment and monthly household income, along with their child's date of birth, sex and ethnicity. Height and weight of the adolescents were measured using standard procedures at school. BMI $\left(\mathrm{kg} / \mathrm{m}^{2}\right)$ was calculated as weight $/$ height $^{2}$. Z-score for BMI-for-age was determined using WHO AnthroPlus Version $1 \cdot 0 \cdot 3$ software $^{(24)}$ and categorized using the WHO Growth Reference $2007^{(25)}$.

\section{Semi-quantitative FFQ}

The semi-quantitative FFQ was adapted from the Malaysian Adult Nutrition Survey $2003^{(26)}$. The semi-quantitative FFQ includes ninety-six food items with standardized serving sizes described using natural portions (e.g. 1 whole apple, 1 piece of chicken and 1 slice of pizza) or usual household measurements (e.g. 1 plate of rice, 1 medium bowl of porridge and 1 glass of ultra heat-treated milk). Adolescents were asked the frequency of intake of each food item over the past month and the number of servings per intake.

The frequency of intake of each food item was then converted into servings per day by multiplying the conversion factor of the frequency of intake ${ }^{(27)}$ with the number of servings per intake. For example, if an adolescent consumed pizza twice weekly and one piece each time, the servings per day would be $2 / 7$ or 0.29 multiplied by 1 , which is equal to $0 \cdot 29$ servings/d. The servings per day of each of the food items were used in the construction of the dietary patterns.

\section{Food grouping}

The ninety-six food items in the semi-quantitative FFQ were grouped into thirty-eight food groups based on their nutrient profile similarities and the socio-cultural context of the way the foods are usually consumed (Table 1). Some of the food items were retained due to their distinct characteristics or importance in describing adolescents' diet. Food grouping is useful in minimizing within-person variations in intake for each of the food items ${ }^{(28)}$.

Table 1 Food groupings for construction of the dietary patterns

\begin{tabular}{|c|c|}
\hline Food group & Food items \\
\hline Rice & Rice, porridge \\
\hline Noodles & Wheat noodles, rice noodles \\
\hline Pasta & Pasta \\
\hline Bread & Bread \\
\hline Buns & Buns \\
\hline Unleavened bread (roti canal) & Unleavened bread (roti canai) \\
\hline Cereals & Breakfast cereals, instant cereals \\
\hline Pizza & Pizza \\
\hline Chicken & Chicken \\
\hline Red meat & Beef, goat/lamb \\
\hline Processed meat & Burger, sausage, nugget, chicken/seafood balls \\
\hline Fish & Marine fish, freshwater fish, anchovy, canned fish \\
\hline Seafood & Cockles, prawn, cuttlefish/squid, crab \\
\hline Salted, dried fish & Salted, dried fish \\
\hline Processed fish & Fish balls \\
\hline Fish snacks & Fried flour-coated fish fillet \\
\hline Eggs & Chicken eggs, quail eggs, salted eggs \\
\hline Nuts and soybean products & Nuts/pulses, peanuts, soyabean curd, fermented soya \\
\hline Milk & Ultra heat-treated milk, powdered milk \\
\hline Dairy products & Yoghurt, cheese \\
\hline Green leafy vegetables & All types, e.g. mustard leaves, spinach, swamp cabbage \\
\hline Cruciferous vegetables & All types, e.g. cabbages, cauliflower, broccoli \\
\hline Legumes & All types, e.g. French beans, angled beans, ladies finger \\
\hline Tubers & All types, e.g. potatoes, sweet potatoes, carrots \\
\hline Other vegetables & Cucumber/brinjal/pumpkin, salad, baby corn, corn, mushroom, bean sprouts \\
\hline Fruits & $\begin{array}{l}\text { Papaya, guava, local orange/mandarin orange, mango, pineapple, banana, watermelon, star fruit, } \\
\text { apple, orange, pear, grape, longan, honeydew }\end{array}$ \\
\hline High-energy beverages & Carbonated drinks, cordials, energy drinks, chocolate drinks, malted drinks, fruit juices, soyabean milk \\
\hline Tea and coffee & Tea, coffee \\
\hline Pastries & Cakes, traditional cakes, biscuits \\
\hline Sweets & Sweets, lollipops \\
\hline Ice cream & Ice cream \\
\hline Shaved ice and jellies & Shaved ice, jellies \\
\hline Snacks & Snacks \\
\hline Butter & Butter \\
\hline Margarine & Margarine \\
\hline Spreads & Jams, coconut jam, peanut butter, honey \\
\hline Condiments & Sugar, sweetened condensed milk, evaporated milk \\
\hline Sauces & Chilli/tomato sauce, soya sauce, oyster sauce, prawn chilli paste \\
\hline
\end{tabular}




\section{Cognitive ability}

Cognitive ability was assessed using the Wechsler Nonverbal Scale of Ability ${ }^{(29)}$. This instrument measures general cognitive ability non-verbally and is therefore useful in assessing children and adolescents of the nonEnglish speaking community ${ }^{(29)}$. There are four subtests in the Wechsler Nonverbal Scale of Ability, which are matrices, coding, spatial span and picture arrangement.

The matrices assessed perceptual reasoning. In this task the adolescents were asked to look at an incomplete matrix figure and identify the missing portion from the options provided. Altogether there are forty-one items in the matrices and the difficulty level increases in a progressive manner. Each correct answer is given a score of 1 .

The coding task assessed processing speed by asking the adolescent to rewrite a set of numbers in their given symbols within $120 \mathrm{~s}$. A score of 1 is given for each correct answer. The maximum possible score is 144 .

The spatial span test assessed working memory. In this test, the adolescent was asked to repeat a sequence of block tapping performed by the researcher in both forward and backward manners. The number of blocks being tapped increases progressively. There are sixteen items in this test, eight items to be tapped forwards and eight items to be tapped backwards. Each item consists of two trials, and each correct trial is given a score of 1 .

Picture arrangement assessed perceptual organization. This test requires the adolescent to rearrange a set of pictures so as to tell a logical story within a stipulated time ${ }^{(30)}$. There are thirteen items in this test and the level of difficulty increases in a progressive manner. Each correct item is given a score of 2, except for item numbers 11 and 12, which might be given a score of either 1 or 2 according to the response.

For each of the subtests, the raw score is converted into a standardized score that is adjusted for age using a conversion table provided by the test provider. The general cognitive ability score is a composite score of the standardized subtest scores, which include scores on matrices, coding, spatial span and picture arrangement. The standardized score for each of the subtests has a mean of 50 and an SD of 10, whereas the general cognitive ability standardized score has a mean of 100 and an SD of $15^{(29)}$. The internal consistencies (Cronbach's $\alpha$ ) for matrices, coding, spatial span, picture arrangement and the general cognitive ability score in the present study were $0 \cdot 96,0 \cdot 85,0 \cdot 75,0 \cdot 64$ and $0 \cdot 93$, respectively.

\section{Data analysis}

Data were analysed using the statistical software package IBM SPSS Statistics version 19. Dietary patterns were constructed using principal component analysis. Servings per day of each of the thirty-eight food groups were used in the analysis of the dietary patterns. The factors were rotated by an orthogonal transformation using Varimax rotation in IBM SPSS Statistics. The factors were extracted and retained based on eigenvalues $>1$, break-point in the scree plot and interpretability of the factors. Food groups with factor loadings less than the absolute value of $0 \cdot 30$ were excluded. The Kaiser-Meyer-Olkin measure of sampling adequacy was 0.76 (Bartlett's test of sphericity, $P<0 \cdot 001$ ). Dietary pattern scores were calculated by summing the servings per day intake of each food group weighted by the loading of the food groups. Adolescents were given a score for each of the patterns.

The associations between continuous variables and cognitive ability were determined using Pearson productmoment correlation. The mean differences in cognitive ability according to sex and parents' educational attainment were determined using independent-sample $t$ tests. Comparison between parents' educational attainment and dietary pattern scores was conducted using the Mann-Whitney $U$ test. A multiple linear regression analysis was conducted using the hierarchical method. Indicators of socio-economic status including monthly household income and parents' educational attainment were entered in the first block. A dietary pattern that was found to have a significant association with general cognitive ability score at the bivariate level was entered in the second block. The level of significance was set at $P<0 \cdot 05$.

\section{Results}

\section{Sociodemographic background, sample characteristics and cognitive ability}

The total number of adolescents who participated in the study was 416 , where $38.7 \%$ of them were boys and $61 \cdot 3 \%$ were girls. The mean age was $12 \cdot 4$ (SD $0 \cdot 49)$ years. Most of their fathers attained tertiary education $(50 \cdot 0 \%)$, while most of their mothers attained secondary education $(47 \cdot 2 \%)$. The mean monthly household income in Malaysian Ringgit was RM4383.1 (SD 4110.7), which is equivalent to $\$$ US $1371 \cdot 4$ (SD $1286 \cdot 2$ ). For cognitive ability, the mean general cognitive ability score was $101 \cdot 8$ (SD 12.4). The mean score for perceptual organization was the lowest $($ mean $=45 \cdot 5, \mathrm{SD}=8 \cdot 7$ ) compared with the mean scores of the other cognitive domains (Table 2). The prevalence of overweight and obesity in the total sample was $20 \cdot 4 \%$ and $15 \cdot 1 \%$, respectively. Among girls, $19.6 \%$ were overweight and $12.9 \%$ were obese, while the prevalence of overweight and obesity for boys was $21.7 \%$ and $18.6 \%$, respectively (Table 3 ).

\section{Dietary patterns}

Four major factors were extracted from the principal component analysis and labelled as 'refined-grain pattern', 'snack-food pattern', 'plant-based food pattern' and 'high-energy food pattern'. These patterns explained $17 \cdot 8 \%, 8 \cdot 8 \%, 6 \cdot 5 \%$ and $6 \cdot 0 \%$ of the variance in habitual dietary intakes, respectively. The internal consistencies (Cronbach's $\alpha$ ) for the patterns were $0.68,0 \cdot 76,0.63$ 
Table 2 Study characteristics of the urban adolescents ( $n$ 416), Gombak District, Selangor, Malaysia, July 2011March 2012

\begin{tabular}{|c|c|c|c|c|}
\hline Characteristic & $n$ & $\%$ & Mean & SD \\
\hline \multicolumn{5}{|l|}{ Sociodemographic background } \\
\hline Age (years) & & & $12 \cdot 4$ & 0.5 \\
\hline 12 & 242 & $58 \cdot 2$ & & \\
\hline 13 & 174 & $41 \cdot 8$ & & \\
\hline \multicolumn{5}{|l|}{ Sex } \\
\hline Male & 161 & $38 \cdot 7$ & & \\
\hline Female & 255 & $61 \cdot 3$ & & \\
\hline Monthly household income (RM)† & & & $4383 \cdot 1$ (\$US 1371·4) & $4110 \cdot 7$ (\$US 1286.2) \\
\hline \multicolumn{5}{|l|}{ Father's education levelł } \\
\hline Secondary education and below & 195 & $50 \cdot 0$ & & \\
\hline Tertiary education & 195 & $50 \cdot 0$ & & \\
\hline \multicolumn{5}{|l|}{ Mother's education level§̧ } \\
\hline Secondary education and below & 225 & $55 \cdot 3$ & & \\
\hline Tertiary education & 182 & $44 \cdot 7$ & & \\
\hline \multicolumn{5}{|l|}{ Anthropometric measures } \\
\hline Weight (kg) & & & $47 \cdot 7$ & $14 \cdot 0$ \\
\hline Height $(\mathrm{cm})$ & & & $152 \cdot 1$ & $7 \cdot 2$ \\
\hline BMI $\left(\mathrm{kg} / \mathrm{m}^{2}\right)$ & & & $20 \cdot 5$ & $5 \cdot 2$ \\
\hline BMl-for-age Z-score & & & $0 \cdot 3$ & $1 \cdot \overline{6}$ \\
\hline \multicolumn{5}{|l|}{ Cognitive ability } \\
\hline Perceptual reasoning & & & $49 \cdot 8$ & $9 \cdot 6$ \\
\hline Processing speed & & & $55 \cdot 2$ & $7 \cdot 7$ \\
\hline Working memory & & & $53 \cdot 4$ & $8 \cdot 8$ \\
\hline Perceptual organization & & & $45 \cdot 5$ & $8 \cdot 8$ \\
\hline General cognitive ability & & & $101 \cdot 8$ & $12 \cdot 4$ \\
\hline
\end{tabular}

RM, Malaysian Ringgit.

tMonthly household income, $n 393$.

¥Father's education level, $n$ 390.

\$Mother's education level, $n 407$.

Table 3 Distribution of BMI status among the urban adolescents ( $n$ 416) aged 12 to 13 years, Gombak District, Selangor, Malaysia, July 2011-March 2012

\begin{tabular}{|c|c|c|c|c|c|c|}
\hline \multirow[b]{2}{*}{ BMI status } & \multicolumn{2}{|c|}{ Boys (n 161) } & \multicolumn{2}{|c|}{ Girls (n 255) } & \multicolumn{2}{|c|}{ Total $(n 416)$} \\
\hline & $n$ & $\%$ & $n$ & $\%$ & $n$ & $\%$ \\
\hline Severely thin & 2 & $1 \cdot 2$ & 6 & $2 \cdot 4$ & 8 & $1 \cdot 9$ \\
\hline Thin & 7 & $4 \cdot 3$ & 15 & $5 \cdot 9$ & 22 & $5 \cdot 3$ \\
\hline Normal & 87 & $54 \cdot 0$ & 151 & $59 \cdot 2$ & 238 & $57 \cdot 2$ \\
\hline Overweight & 35 & $21 \cdot 7$ & 50 & $19 \cdot 6$ & 85 & $20 \cdot 4$ \\
\hline Obese & 30 & $18 \cdot 6$ & 33 & $12 \cdot 9$ & 63 & $15 \cdot 1$ \\
\hline
\end{tabular}

and $0 \cdot 51$, respectively. Foods that loaded highly on the refined-grain pattern were unleavened bread (roti canai), buns, pizza, pasta and rice. Dairy products, pastries, bread, cereals, fruits, chicken and milk loaded highly on the snack-food pattern. Green leafy vegetables, other vegetables, cruciferous vegetables, nuts and soyabean products, legumes and tubers loaded highly on the plantbased food pattern. The high-energy food pattern was highly loaded with noodles, eggs, processed meat and fish snacks (Table 4).

\section{Sociodemographic background and cognitive ability}

Monthly household income was found to be positively correlated with general cognitive ability $(r=0 \cdot 24, P<0 \cdot 01)$ and all four domains of cognitive ability (Table 5). Adolescents whose fathers had a tertiary education performed significantly better $($ mean $=104 \cdot 6, \quad \mathrm{SD}=12 \cdot 1)$ on the cognitive tasks compared with those whose fathers had secondary education or less $($ mean $=98 \cdot 6, \mathrm{SD}=11 \cdot 8)$. Adolescents whose mothers attained tertiary education also obtained significantly higher cognitive scores (mean $=104 \cdot 6, \mathrm{sD}=12 \cdot 7)$ compared with those whose mothers had secondary education or less (mean $=99 \cdot 6$, $\mathrm{SD}=11 \cdot 7)$. Girls scored significantly higher $($ mean $=57 \cdot 0$, $\mathrm{SD}=6 \cdot 8)$ in processing speed compared with boys (mean $=52 \cdot 3, \mathrm{SD}=8 \cdot 1)$. However, boys had significantly better $($ mean $=48 \cdot 4, \mathrm{SD}=8 \cdot 3$ ) perceptual organization than girls $($ mean $=43 \cdot 8, \mathrm{SD}=8 \cdot 6$; Table 6$)$.

\section{Dietary patterns and cognitive ability}

The refined-grain pattern was found to be negatively associated with processing speed $(r=-0 \cdot 11, P<0 \cdot 05)$. Scores on the high-energy food pattern were negatively associated with perceptual reasoning $(r=-0 \cdot 11$, $P<0 \cdot 05)$, processing speed $(r=-0 \cdot 12, P<0 \cdot 05)$ and general cognitive ability $(r=-0 \cdot 15, P<0 \cdot 01)$. The snackfood pattern and plant-based pattern were negatively associated with general cognitive ability; however, the associations were insignificant (Table 7).

\section{Parents' educational attainment and dietary patterns}

It was found that adolescents whose mothers had tertiary education had significantly lower scores for the highenergy food pattern $($ mean $\mathrm{rank}=180 \cdot 1)$ compared with 
Table 4 Factor-loading matrixt for the dietary patterns identified ( $n$ 416)

\begin{tabular}{|c|c|c|c|c|}
\hline Food group & Refined-grain pattern & Snack-food pattern & Plant-based food pattern & High-energy food pattern \\
\hline Roti canai & 0.90 & & & \\
\hline Buns & 0.89 & & & \\
\hline Pizza & $0 \cdot 72$ & & & \\
\hline Pasta & 0.49 & & & \\
\hline Rice & 0.32 & & & \\
\hline Dairy products & & $0 \cdot 78$ & & \\
\hline Pastries & & 0.63 & & \\
\hline Bread & & 0.62 & & \\
\hline Cereals & & 0.61 & & \\
\hline Fruits & & 0.58 & & \\
\hline Chicken & & 0.40 & & \\
\hline Milk & & 0.37 & & \\
\hline Green leafy vegetables & & & $0 \cdot 77$ & \\
\hline Other vegetables & & & 0.68 & \\
\hline Cruciferous vegetables & & & 0.61 & \\
\hline Nuts and soyabean products & & & 0.39 & \\
\hline Legumes & & & 0.38 & \\
\hline Tubers & & & 0.33 & \\
\hline Noodles & & & & 0.73 \\
\hline Eggs & & & & 0.64 \\
\hline Processed meat & & & & 0.46 \\
\hline Fish snacks & & & & 0.39 \\
\hline
\end{tabular}

tOnly food groups with absolute factor loadings $>0.30$ were retained in each pattern.

Table 5 Correlation (Pearson $r$ ) between monthly household income and cognitive ability among the urban adolescents ( $n 393$ ) aged 12 to 13 years, Gombak District, Selangor, Malaysia, July 2011-March 2012

\begin{tabular}{lccccc}
\hline Variable & $\begin{array}{c}\text { Perceptual } \\
\text { reasoning }\end{array}$ & $\begin{array}{c}\text { Processing } \\
\text { speed }\end{array}$ & $\begin{array}{c}\text { Working } \\
\text { memory }\end{array}$ & $\begin{array}{c}\text { Perceptual } \\
\text { organization }\end{array}$ & $\begin{array}{c}\text { General } \\
\text { cognitive ability }\end{array}$ \\
\hline Monthly household income (RM) & $0 \cdot 17^{\star *}$ & $0 \cdot 19^{\star *}$ & $0 \cdot 15^{\star *}$ & $0 \cdot 13^{*}$ & $0 \cdot 24^{\star *}$ \\
\hline
\end{tabular}

RM, Malaysian Ringgit.

${ }^{\star} P<0.05 ;{ }^{* *} P<0.01$.

Table 6 Differences ( $t$ test) in cognitive ability according to sex and parents' educational attainment among the urban adolescents aged 12 to 13 years, Gombak District, Selangor, Malaysia, July 2011-March 2012

\begin{tabular}{|c|c|c|c|c|c|c|c|c|c|c|c|}
\hline \multirow[b]{2}{*}{ Variable } & \multirow[b]{2}{*}{$n$} & \multicolumn{2}{|c|}{$\begin{array}{l}\text { Perceptual } \\
\text { reasoning }\end{array}$} & \multicolumn{2}{|c|}{ Processing speed } & \multicolumn{2}{|c|}{ Working memory } & \multicolumn{2}{|c|}{$\begin{array}{l}\text { Perceptual } \\
\text { organization }\end{array}$} & \multicolumn{2}{|c|}{$\begin{array}{c}\text { General cognitive } \\
\text { ability }\end{array}$} \\
\hline & & Mean & SD & Mean & SD & Mean & SD & Mean & SD & Mean & SD \\
\hline \multicolumn{12}{|l|}{ Sex } \\
\hline Male & 161 & $50 \cdot 8$ & $9 \cdot 9$ & $52 \cdot 3$ & $8 \cdot 1$ & $54 \cdot 3$ & $9 \cdot 2$ & $48 \cdot 4$ & $8 \cdot 3$ & $102 \cdot 8$ & $12 \cdot 2$ \\
\hline Female & 255 & $49 \cdot 2$ & $9 \cdot 3$ & $57 \cdot 0$ & $6 \cdot 8$ & $52 \cdot 8$ & $8 \cdot 5$ & $43 \cdot 8$ & $8 \cdot 6$ & $101 \cdot 1$ & $12 \cdot 4$ \\
\hline$t$ & & \multirow{2}{*}{\multicolumn{2}{|c|}{$1 \cdot 7$}} & \multicolumn{2}{|c|}{$6 \cdot 2^{\star \star}$} & \multirow{2}{*}{\multicolumn{2}{|c|}{$1 \cdot 8$}} & \multicolumn{2}{|c|}{$5 \cdot 4^{\star \star}$} & \multicolumn{2}{|c|}{$1 \cdot 7$} \\
\hline \multicolumn{10}{|c|}{ Father's educational attainment } & & \\
\hline Secondary and below & 195 & $47 \cdot 8$ & $8 \cdot 7$ & 53.5 & $7 \cdot 8$ & $52 \cdot 7$ & $8 \cdot 6$ & 43.9 & 0.6 & $98 \cdot 6$ & $11 \cdot 8$ \\
\hline Tertiary & 195 & $51 \cdot 7$ & $9 \cdot 9$ & $56 \cdot 9$ & $7 \cdot 3$ & $54 \cdot 2$ & $8 \cdot 4$ & $47 \cdot 0$ & 0.6 & $104 \cdot 6$ & $12 \cdot 1$ \\
\hline${ }^{t}$ & & \multicolumn{2}{|c|}{$-4 \cdot 1^{\star \star}$} & \multicolumn{2}{|c|}{$-4 \cdot 5^{\star *}$} & \multicolumn{2}{|c|}{$-1 \cdot 8$} & \multicolumn{2}{|c|}{$-3 \cdot 5^{\star}$} & \multicolumn{2}{|c|}{$-5 \cdot 3^{\star \star}$} \\
\hline Secondary and below & 225 & & 8.7 & & & 52.5 & 8.5 & & & & \\
\hline Tertiary & 182 & $51 \cdot 2$ & $10 \cdot 5$ & $56 \cdot 8$ & $7 \cdot 2$ & $54 \cdot 3$ & $9 \cdot 0$ & $46 \cdot 7$ & $8 \cdot 7$ & $104 \cdot 6$ & $12 \cdot 7$ \\
\hline$t$ & & \multicolumn{2}{|c|}{$-2 \cdot 6^{*}$} & \multicolumn{2}{|c|}{$-3 \cdot 7^{\star *}$} & \multicolumn{2}{|c|}{$-2 \cdot 1^{*}$} & \multicolumn{2}{|c|}{$-2 \cdot 4^{*}$} & \multicolumn{2}{|c|}{$-4 \cdot 1^{\star \star}$} \\
\hline
\end{tabular}

${ }^{*} P<0.05 ;{ }^{* *} P<0.01$

those whose mothers had secondary education or less (mean $\mathrm{rank}=207 \cdot 6$; Table 8 ).

\section{Factors contributing towards general cognitive ability}

Socio-economic status as indicated by monthly household income, father's educational attainment and mother's educational attainment were found to contribute significantly towards general cognitive ability $\left(R^{2}=0 \cdot 108\right.$, $F=14 \cdot 024, \quad P<0 \cdot 001)$. The high-energy food pattern was also found to contribute significantly towards general cognitive ability $\left(\Delta R^{2}=0 \cdot 017, \Delta F=6 \cdot 849\right.$, $P<0 \cdot 01)$ after controlling for socio-economic status, which included monthly household income, father's 
Table 7 Correlation (Pearson $r$ ) between dietary patterns and cognitive ability among the urban adolescents ( $n 397)$ aged 12 to 13 years, Gombak District, Selangor, Malaysia, July 2011-March 2012

\begin{tabular}{|c|c|c|c|c|c|}
\hline Variable & Perceptual reasoning & Processing speed & Working memory & Perceptual organization & General cognitive ability \\
\hline Refined-grain pattern & -0.01 & $-0 \cdot 11^{*}$ & 0.08 & 0.06 & 0.01 \\
\hline Snack-food pattern & 0.01 & -0.03 & 0.01 & -0.03 & -0.01 \\
\hline Plant-based food pattern & -0.01 & -0.04 & 0.01 & -0.07 & -0.04 \\
\hline High-energy food pattern & $-0 \cdot 11^{*}$ & $-0 \cdot 12^{*}$ & -0.06 & -0.09 & $-0 \cdot 15^{\star *}$ \\
\hline
\end{tabular}

${ }^{\star} P<0.05 ;{ }^{* \star} P<0.01$.

Table 8 Differences (Mann-Whitney $U$ test) in dietary pattern scores according to parents' educational attainment among the urban adolescents aged 12 to 13 years, Gombak District, Selangor, Malaysia, July 2011-March 2012

\begin{tabular}{|c|c|c|c|c|c|}
\hline \multirow[b]{2}{*}{ Variable } & \multirow[b]{2}{*}{$n$} & \multicolumn{4}{|c|}{ Mean rank } \\
\hline & & Refined-grain pattern & Snack-food pattern & Plant-based food pattern & High-energy food pattern \\
\hline \multicolumn{6}{|c|}{ Father's educational attainment } \\
\hline Secondary and below & 184 & $185 \cdot 1$ & $183 \cdot 8$ & $192 \cdot 6$ & $198 \cdot 1$ \\
\hline Tertiary & 189 & $188 \cdot 9$ & $190 \cdot 1$ & $181 \cdot 5$ & $176 \cdot 2$ \\
\hline$Z$ & & -0.3 & -0.6 & $-1 \cdot 0$ & $-2 \cdot 0$ \\
\hline Mann-Whitney $U$ & & 17033.5 & $16799 \cdot 0$ & $16351 \cdot 0$ & $15346 \cdot 5$ \\
\hline \multicolumn{6}{|c|}{ Mother's educational attainment } \\
\hline Secondary and below & 211 & $194 \cdot 7$ & $189 \cdot 4$ & $199 \cdot 1$ & $207 \cdot 6$ \\
\hline Tertiary & 178 & $195 \cdot 4$ & $201 \cdot 7$ & $190 \cdot 1$ & $180 \cdot 1$ \\
\hline$Z$ & & -0.1 & $-1 \cdot 1$ & $-0 \cdot 8$ & $-2 \cdot 4$ \\
\hline Mann-Whitney $U$ & & $18717 \cdot 0$ & $17596 \cdot 0$ & 17913.5 & $16120 \cdot 5^{*}$ \\
\hline
\end{tabular}

${ }^{*} P<0.05$.

Table 9 Multiple linear regression analysis (hierarchical) of factors contributing towards general cognitive ability among the urban adolescents ( $n$ 350) aged 12 to 13 years, Gombak District, Selangor, Malaysia, July 2011-March 2012

\begin{tabular}{lrrrr}
\hline Variable & \multicolumn{1}{c}{ F } & \multicolumn{1}{c}{$P$} & $R^{2}$ \\
\hline & 12.408 & & $<0.001$ & 0.126 \\
Constant & & 102.763 & $<0.001$ & \\
Socio-economic status & & 0.001 & 0.013 \\
$\quad$ Monthly household income & 3.118 & 0.031 & \\
$\quad$ Father's educational attainmentt & & 1.211 & 0.407 & \\
$\quad$ Mother's educational attainmentt & & -0.459 & 0.009 & \\
High-energy food pattern & & &
\end{tabular}

tReference group for father and mother's educational attainment is secondary education and below.

educational attainment and mother's educational attainment (Table 9). Overall, socio-economic status and the high-energy food pattern explained about $12 \cdot 6 \%$ of the variance in general cognitive ability.

\section{Discussion}

In the present study we have identified four major dietary patterns among the adolescents, which are refined-grain pattern, snack-food pattern, plant-based food pattern and high-energy food pattern. Foods in the refined-grain pattern showed a combination of traditional Malaysian diets and Westernized diets. The snack-food pattern found in the study consists of foods that are commonly found in school cafeterias in Malaysia, which include bread, pastries and fruits. The plant-based food pattern includes vegetables as well as nuts and soyabean products, whereas the high-energy food pattern is characterized by the high loading of noodles, eggs, processed meats and fish snacks. These foods require minimal preparation, where they are usually fried and contain high amounts of fat.

Adolescents who had higher scores for the high-energy pattern in the present study were found to have lower general cognitive ability as well as perceptual reasoning and processing speed. The types of meals in this pattern possess high energy and sodium content and low nutritional value ${ }^{(31)}$. In the Growing Up in Scotland (GUS) study, Von Stumm ${ }^{(31)}$ found that consumption of slow-food meals in contrast with fast-food meals was associated with better cognitive ability among Scottish children. However, the author also found that children from higher socio-economic status performed better in the cognitive tests and that the frequency of consumption of slow-food meals was also higher among them ${ }^{(31)}$. In the present study, monthly household income, which is an indicator of socio-economic status, was also found to have a positive correlation with general cognitive ability. Socio-economic status plays an important role in the cognitive development of an individual ${ }^{(32)}$. Children from families with low socio-economic status tend to have inadequate nutrient intakes, poorer health status and lack a cognitively stimulating environment ${ }^{(33)}$. However, after controlling for socio-economic status, which includes monthly household income, father's educational 
attainment and mother's educational attainment in the multivariate analysis, the high-energy food pattern in the present study remained significantly contributing towards general cognitive ability.

$\mathrm{Fu}$ et $a l^{(17)}$ have found that an unhealthful eating pattern, which was described as a high intake of lowquality foods such as sweets and fried foods, was associated with lower school performance among Taiwanese children. Higher parental education level was also found to be negatively associated with unhealthful eating pattern among the children ${ }^{(17)}$. In the present study, we have also found that adolescents whose mothers had tertiary education had lower scores for the high-energy food pattern compared with those whose mothers had secondary education or less. Adolescents whose parents had attained tertiary education also tended to have higher general cognitive ability compared with those whose parents had secondary education or less.

In the 1970 British Cohort Study, Batty et al. ${ }^{(34)}$ found that higher mental ability of a cohort of children at the age of 10 years was associated with healthier eating habits as adults at the age of 30 years among the cohort. Therefore, it is also possible that adolescents with higher cognitive ability tend to eat more healthily than those with lower cognitive ability.

High consumption of foods in the refined-grain pattern was found to be associated with lower processing speed. The foods in this pattern are carbohydrate-based foods with high glycaemic index (GI). Studies on different types of carbohydrate have found that foods with low GI tend to be more beneficial towards cognitive functioning in children compared with foods with high $\mathrm{GI}^{(35-38)}$. This is because high-GI foods contain carbohydrates that break down quickly resulting in a rapid rise of blood glucose levels, while foods with low GI have slower carbohydrate conversion resulting in a more gradual and steady increase of blood glucose levels, thus sustenance of energy to the brain ${ }^{(39)}$.

It is worth noting that the internal consistencies for the spatial span test, picture arrangement test and most of the dietary patterns were low in our study. Therefore, the results should be interpreted with caution, especially when considering the relationship between the subtests scores of cognitive ability and dietary patterns. The results should not be generalized to the population since there may be other factors that influence the relationship observed between the dietary patterns and cognitive ability among the adolescents.

One of the factors might be breakfast consumption. Previous studies have shown that breakfast consumption improves cognitive ability among children and adolescents ${ }^{(35-37,40)}$. For example, in a study by Wesnes et al. ${ }^{(35)}$, consumption of breakfast cereals was found to improve memory and processing speed of children aged 9 to 16 years. It has also been found that children who eat breakfast consistently tend to have superior nutritional profiles than those who skip breakfast ${ }^{(40)}$. Children who skip breakfast were also found to be adopting unhealthy dietary habits ${ }^{(41)}$.

Another factor that might influence the relationship between dietary patterns and cognitive ability among the adolescents might be the Fe status of the adolescents. $\mathrm{Fe}$ is an essential micronutrient that plays a major role in oxidation-reduction reactions, synthesis and catabolism of neurotransmitters as well as production of myelin ${ }^{(42)}$. Fe-deficiency anaemia was found to be associated with poor cognitive and motor development in children as well as behavioural problems in middle childhood ${ }^{(43)}$. In a local study by Hamid Jan et al. ${ }^{(44)}$, Fe-deficient children with and without anaemia were found to score significantly lower in problem-solving tests and had a lower general cognitive ability score compared with their healthy counterparts. Fe status was not measured in the present study, however.

\section{Limitations}

One of the limitations of the present study is the inclusion of only one ethnic group in Malaysia, namely Malay. This was mainly due to language barriers, where in the pre-test of our study we found that adolescents of other ethnicities had difficulties in naming and explaining the foods that they consumed in the national language, which is Bahasa Malaysia. The variation of diets across ethnicity might also complicate the analysis, thus we decided to include only one ethnic group. Although maternal intelligence was not measured in the study, mother's educational attainment can be used as a proxy for maternal intelligence and this factor was controlled for in the multivariate analysis. However home environment, which may plays an important role in cognitive stimulation, was not measured in our study. Another limitation is the small number of similar studies with which to compare. To our knowledge, there is no publication locally that has examined the dietary patterns of Malaysian adolescents. Thus, the present study's findings might provide an insight into the dietary patterns of adolescents in Malaysia and their associations with cognitive ability among adolescents.

\section{Conclusion}

Four major dietary patterns were identified among the urban Malay adolescents in the district of Gombak in Selangor, Malaysia. The major dietary patterns included refined-grain pattern, snack-food pattern, plant-based food pattern and high-energy food pattern. High consumption of foods in the high-energy food pattern was found to be associated with lower scores on general cognitive ability as well as perceptual reasoning and processing speed. The association between the high-energy food pattern and general cognitive ability remained significant even after controlling for socio-economic status, which included 
monthly household income, father's education attainment and mother's education attainment.

\section{Acknowledgements}

Sources of funding: This study was funded by the Research University Grant Scheme (Project number: 04-02-11-1382RU). The Research University Grant Scheme had no role in the design, analysis or writing of this article. Conflict of interest: The authors have no conflicts of interest. Authors' contributions: A.R.N. conducted the study, performed the data analysis and wrote the manuscript; M.T.M.N. supervised the study and edited the manuscript; M.S.Z. consulted on the dietary pattern analysis; A.R. provided the instrument and training for the cognitive testing.

\section{References}

1. Spear LP (2000) The adolescent brain and age-related behavioral manifestations. Neurosci Biobehav Rev 24, 417-463.

2. Steinberg L (2010) A behavioral scientist looks at the science of adolescent brain development. Brain $\operatorname{Cog} n \mathbf{7 2}$, 160-164.

3. Fuster JM (2002) Frontal lobes and cognitive development. J Neurocytol 31, 373-385.

4. Benton D (2010) The influence of dietary status on the cognitive performance of children. Mol Nutr Food Res $\mathbf{5 4}$, $457-470$.

5. Benton D \& Stevens MK (2008) The influence of a glucose containing drink on the behavior of children in school. Biol Psychol 78, 242-245.

6. Bruner AB, Joffe A, Duggan AK et al. (1996) Randomized study of cognitive effects of iron supplementation in non-anaemic iron-deficient adolescent girls. Lancet $\mathbf{3 4 8}$, 992-996.

7. Schoenthaler SJ, Bier ID, Young K et al. (2000) The effects of vitamin-mineral supplementation on the intelligence of American schoolchildren: a randomized, double-blind placebo-controlled trial. J Altern Complement Med 6, 19-29.

8. Benton D (2001) Micro-nutrient supplementation and the intelligence of children. Neurosci Behav Rev 25, 297-309.

9. Schulze MB, Hoffmann K, Kroke A et al. (2003) An approach to construct simplified measures of dietary patterns from exploratory factor analysis. Br J Nutr 89, $409-418$.

10. Hu FB (2002) Dietary pattern analysis: a new direction in nutritional epidemiology. Curr Opin Lipidol 13, 3-9.

11. McNaughton SA, Ball K, Mishra GD et al. (2008) Dietary patterns of adolescents and risk of obesity and hypertension. J Nutr 138, 346-370.

12. Cutler GJ, Flood A, Hannan P et al. (2011) Multiple sociodemographic and socioenvironmental characteristics are correlated with major patterns of dietary intake in adolescents. J Am Diet Assoc 111, 230-240.

13. Kant AK (2004) Dietary patterns and health outcomes. J Am Diet Assoc 104, 615-635.

14. Gale CR, Martyn CN, Marriott LD et al. (2009) Dietary patterns in infancy and cognitive and neuropsychological function in childhood. J Child Psychol Psychiatry 50, 816-823.
15. Smithers LG, Golley RK, Mittinty MN et al. (2012) Dietary patterns at 6,15 and 24 months of age are associated with IQ at 8 years of age. Eur J Epidemiol 27, 525-535.

16. Oddy WH, Robinson M, Ambrosini GL et al. (2009) The association between dietary patterns and mental health in early adolescence. Prev Med 49, 39-44.

17. Fu ML, Cheng L, Tu SH et al. (2007) Association between unhealthful eating patterns and unfavorable overall school performance in children. J Am Diet Assoc 107, $1935-1943$.

18. Benton D (2008) The influence of children's diet on their cognition and behavior. Eur J Nutr 47, Suppl. 3, 25-37.

19. Breslau N, Dickens WT, Flynn JR et al. (2006) Low birthweight and social disadvantage: tracking their relationship with children's IQ during the period of school attendance. Intelligence 34, 351-362.

20. Story M, Neumark-Sztainer D \& French S (2002) Individual and environmental influences on adolescent eating behaviors. J Am Diet Assoc 102, Suppl. 3, S40-S51.

21. Neumark-Sztainer D, Story M, Hannan PJ et al. (2002) Overweight status and eating patterns among adolescents: where do youths stand in comparison with the Healthy People 2010 Objectives? Am J Public Health 92, 844-851.

22. Ministry of Education Malaysia (2011) Educational Management Information System. List of Secondary Schools in Selangor as of 31 January 2011. http://www.emisportal. moe.gov.my (accessed May 2011).

23. Department of Statistics Malaysia (2010) Population and Housing Census of Malaysia 2010. Putrajaya: Department of Statistics Malaysia.

24. World Health Organization (2009) WHO AnthroPlus for Personal Computers Manual: Software for Assessing Growth of the World's Children and Adolescents. Geneva: WHO.

25. de Onis M, Onyango AW, Borghi E et al. (2007) Development of a WHO growth reference for school-aged children and adolescents. Bull World Health Organ 85, 660-667.

26. Ministry of Health Malaysia (2003) Volume 1: MethodologyMalaysian Adult Nutrition Survey 2003. Putrajaya: Ministry of Health Malaysia.

27. Norimah AK, Safiah M, Jamal K et al. (2008) Food consumption patterns: findings from the Malaysian Adult Nutrition Survey (MANS). Malays J Nutr 14, 25-39.

28. Hu FB, Rimm EB, Stampfer MJ et al. (2000) Prospective study of major dietary patterns and risk of coronary heart disease in men. Am J Clin Nutr 72, 912-921.

29. Wechsler D \& Naglieri JA (2006) Wechsler Nonverbal Scale of Ability. San Antonio, TX: Pearson.

30. Naglieri JA \& Brunnert KA (2009) Wechsler Nonverbal Scale of Ability (WNV). In Practitioner's Guide to Assessing Intellignece \& Achievement, pp. 315-340 [JA Naglieri \& S Goldstein, editors]. Hoboken, NJ: John Wiley \& Sons, Inc.

31. Von Stumm S (2012) You are what you eat? Meal type, socio-economic status and cognitive ability in childhood. Intelligence 40, 576-583.

32. Hackman DA, Farah MJ \& Meaney MJ (2010) Socioeconomic status and the brain: mechanistic insights from human and animal research. Nat Rev Neurosci 11, 651-659.

33. Rosale FJ, Reznick JS \& Zeisel SH (2009) Understanding the role of nutrition in the brain and behavioral development of toddlers and preschool children: identifying and addressing methodological barriers. Nutr Neurosci 12, 190-202.

34. Batty GD, Deary IJ, Schoon I et al. (2007) Childhood mental ability in relation to food intake and physical activity in adulthood: the 1970 British Cohort Study. Pediatrics 119, e38-e45. 
35. Wesnes KA, Pincock C, Richardson D et al. (2003) Breakfast reduces declines in attention and memory over the morning in schoolchildren. Appetite 41, 329-331.

36. Mahoney CR, Taylor HA, Kanarek RB et al. (2005) Effect of breakfast composition on cognitive processes in elementary school children. Physiol Behav 85, 635-645.

37. Ingwersen J, Defeyter MA, Kennedy DO et al. (2007) A low glycaemic index breakfast cereal preferentially prevents children's cognitive performance from declining throughout morning. Appetite 49, 240-244.

38. Mohd Taib MN, Mohd Shariff Z, Wesnes KA et al. (2012) The effect of high lactose-isomaltulose on cognitive performance of young children. A double blind cross-over design study. Appetite 58, 81-87.

39. Schakel S, Schauer R, Himes J et al. (2008) Development of a glycemic index database for dietary assessment. I Food Compost Anal 21, Suppl. 1, S50-S55.
40. Rampersaud GC, Pereira MA, Girard BL et al. (2005) Breakfast habits, nutritional status, body weight, and academic performance in children and adolescents. $J \mathrm{Am}$ Diet Assoc 105, 743-760.

41. Utter J, Scragg R, Mnurchu CN et al. (2007) At-home breakfast consumption among New Zealand children: associations with body mass index and related nutrition behaviors. J Am Diet Assoc 107, 570-576.

42. Hulthén L (2003) Iron deficiency and cognition. Scand J Nutr 47, 152-156.

43. Grantham-McGregor S \& Ani C (2001) A review of studies on the effect of iron deficiency on cognitive development in children. J Nutr 131, 2S-2, 649S-668S.

44. Hamid Jan JM, Amal KM, Rohani A et al. (2010) Association of iron deficiency with or without anemia and cognitive functions among primary school children in Malaysia. Malays J Nutr 16, 261-270. 